\title{
PRODUCT DEVELOPMENT METHODS IN VIRTUAL REALITY
}

\author{
Balzerkiewitz, Hans-Patrick; \\ Stechert, Carsten
}

Ostfalia University of Applied Sciences

\begin{abstract}
The aim of this paper is to show to how far VR technology can help in the implementation of methods in product development. First, an overview of the product development approach and VR technology is given. Then, an evaluation scheme is developed to examine product development methods for their VR suitability. Finally, the results are evaluated and recommendations for future research are given.
\end{abstract}

Keywords: Virtual reality, Design methods, Design methodology

\section{Contact:}

Balzerkiewitz, Hans-Patrick

Ostfalia University of Applied Sciences

Mechanical engineering

Germany

h.balzerkiewitz@ostfalia.de 


\section{INTRODUCTION}

Increasing globalisation and the introduction of new development tools leads to a constant change in product development. Since the release of the Occulus Rift in 2016, the technology of Virtual Reality (VR) more and more becomes an important part of product development. There it supports the process of digital design reviews, ergonomic studies and ensures a better understanding of the product by both the customer and the developer (Freeman et al., 2018; Berg and Vance, 2017; Abdelhameed, 2013). However, these activities only represent about 10-15 percent of product development. VR technology is therefore not seen as a product development-integrated tool, but as one of many special tools. To change this, the authors have set themselves the goal of being able to carry out at least 60 percent of product development activities with VR support. This paper investigates which of the methods used in product development are suitable for VR implementation. The introduction is followed by an overview of the current product development process and VR technology. In chapter 3, a methodology is presented that can be used to evaluate the VR suitability of the various methods used in product development. According to the feature specifications, the methods are examined for their VR suitability. This is done using a few examples. In section 4 the results achieved are evaluated. Based on this, the final section makes recommendations for future research priorities.

\section{STATE OF THE ART}

In this section, the basics of the paper are presented. First, the procedure within product development is discussed. Then an insight into VR technology is given.

\subsection{Product development}

Due to the complexity of the product development process, efforts have been made since the late 19th century to systematise it. Based on the approaches of Wögerbauer (1943) and Kesselring (1954), Pahl and Beitz, among others, have defined the individual steps of the product development process in a generally valid way. Their process model is divided into 4 basic phases (Pahl/Beitz Konstruktionslehre, 2013):

- Planning PhaseIn the planning phase, the actual development task is clarified and planned. For this purpose, the existing market and company situation is analysed and product ideas are formulated. At the end of this phase a list of requirements is available

- In the concept phase, the essential functions of the new product are determined based on the requirements list. In order to implement these functions, the appropriate operating principles are sought. After the technical and economic evaluation, a concrete product concept exists.

- In the design phase, the building structure is first developed. After the rough definition of the product design, the concept is also examined for weak points. The phase ends with the approval of the final draft and a preliminary parts list.

- The elaboration phase serves to develop the production and utilisation documents. The entire product documentation is available for production release.

This and other process models (for example: according to Hubka or Roth) were subsequently incorporated into VDI-guidelines in the 1970's where all findings were combined into a uniform product development model (Pahl/Beitz Konstruktionslehre, 2013). In 1993 the previous guidelines as well as new findings, e.g. by Gero (Gero, 1990), were summarised in VDI guideline 2221. This was updated and republished in 2019 against the background of globalisation, digitalisation and the use of globally distributed development teams. Figure 1 graphically illustrates the activities of the development process according to VDI 2221. As can be seen, the development process is not sequential but iterative. Within the VDI, nine different activities are specified which are to be carried out to develop new products (Verein Deutscher Ingenieure, 2019). In the context of this paper, methods are considered that are used to achieve the objectives of the individual activities listed in the VDI 2221. 


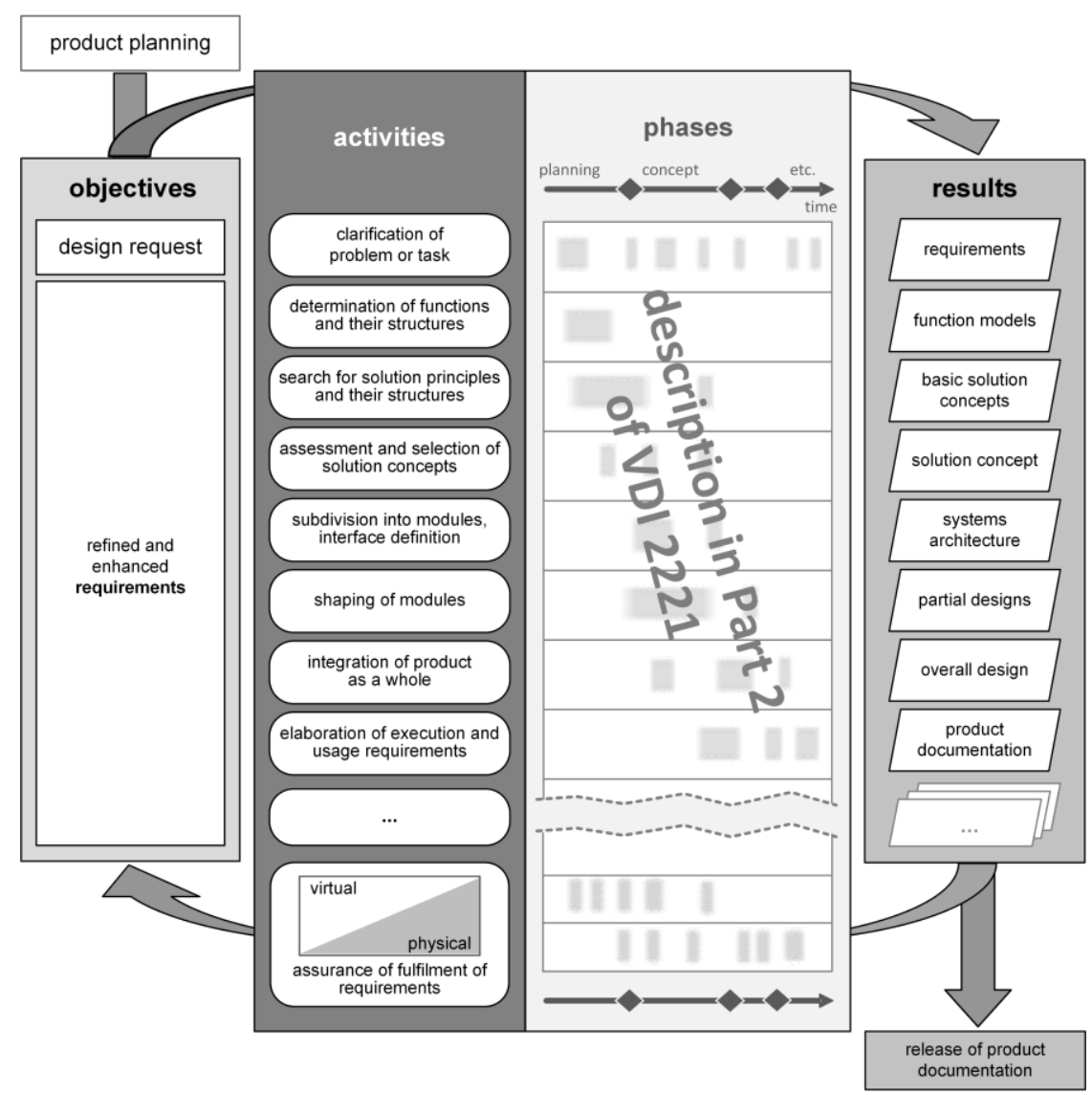

Figure 1. VDI 2221 (Verein Deutscher Ingenieure, 2019)

A method is a procedure based on "a system of rules for obtaining [scientific] knowledge or practical results" (Kunkel-Razum, 2020). In product development, therefore, all processes and procedures used to achieve the objectives of the respective phase are called methods

To illustrate this, the following example is given. The result of the phase search for solution principles and their structures are sketches or models, which shown the principle solution (Verein Deutscher Ingenieure, 2019). A number of different processes and procedures can be used to achieve this. For example the morphological analysis, the method 635 or the brainstorming. These processes and procedures are called methods in the context of this paper. The final selection of the used method depends on the product itself and whether it is a new, adaption or variant design.

\subsection{Virtual Reality in product development}

The first draft of a VR system, the so-called Sensorama, dates back to 1956. In 1968 Ivan Sutherland presented the first head mounted display, the "Sword of Damocles" (Sutherland, 1968). Since then, the technology has been constantly developed and there are many different definitions for the virtual reality.

This paper adopts the definition of (Dionisio et al., 2013):

"VR is a Computer generated simulation of 3-dimensional objects or environments with seemingly real, direct or physical user interaction."

Another definition is given by (Abdelhameed, 2013). Here:

"VR is a Human-Computer interface in which the computer creates a sensory immersing environment that interactively responds to and is controlled by the behaviour of the user."

Each VR system consists of three main components. The software package ensures the communication between the different hardware and software components. The connection between the user and VR is formed by the input devices with which the VR can be manipulated and the output devices through which the effects of the user's actions in the virtual world are returned to him. (Anthes et al., 2016). In order to be perceived as an immersive environment, virtual reality must fulfil the following five characteristics (Abdelhameed, 2013; Rademacher, 2014; Giorgio et al., 2017): 
- A virtual world is the computer-generated space with all the objects it contains. These are administered by rules and relationships.

- The feeling of actually being inside the virtual world is called immersion. This is largely determined by the isolation from the outside world and the possibilities of interaction with the virtual world

- The possibility of interaction describes how users can manipulate the models existing in the virtual world. Manipulation of objects is understood to mean the adaptation of the external appearance of the object, but also more complex processes such as the assembly of components.

- Feedback is the response of the VR system to user input. This is usually visual but can also be acoustic or haptic, for example.

- Participants are the users who interact with the virtual environment and thus manipulate it.

A detailed overview of the VR technology can be found in the already published papers of the authors (Balzerkiewitz and Stechert, 2020a; Balzerkiewitz and Stechert, 2020b). Until 2016, VR was mainly use in the Architecture, Engineering and Construction industry (AEC) With the launch of modern Head Mounted Displays (HMD) like the HTC Vive or the Occulus Rift, VR applications increasingly found their way into technical product development. Here it is mostly used for assembly simulation, ergonomic investigations and design reviews (Hilfert and König, 2016; Zaker and Coloma, 2018; Rademacher, 2014). Figure 2 shows a virtual environment into which a technical product was imported. The product can be viewed in a realistic environment without the need to make prototypes. In this way, ergonomic-aesthetic or technical weaknesses can be quickly identified and eliminated. (Wang et al., 2013; Gong et al., 2019; Berg and Vance, 2017; Kassem et al., 2017). VR offers a simple way of dealing with complex product models. It also enables stakeholders to intervene early in the development of new products.

The methods used so far are characterized by a high degree of complexity. Several persons interact simultaneously with each other and with the product. The session members can operate from different locations. Moreover, they are often from different disciplines. However, current application of VR is limited to only a few methods used in product development. Therefore it is not yet seen as an integrated development tools, but only as a special application that is only used in large or very specialized companies. On the one hand, there is a lack of method-specific VR-tools, on the other hand, the existing methods are not tailored to the use of VR. To ensure that VR is accepted as an integrated tool, the number of feasible activities and thus the number of feasible methods in product development must be significantly increased (Balzerkiewitz and Stechert, 2020a). General methodology

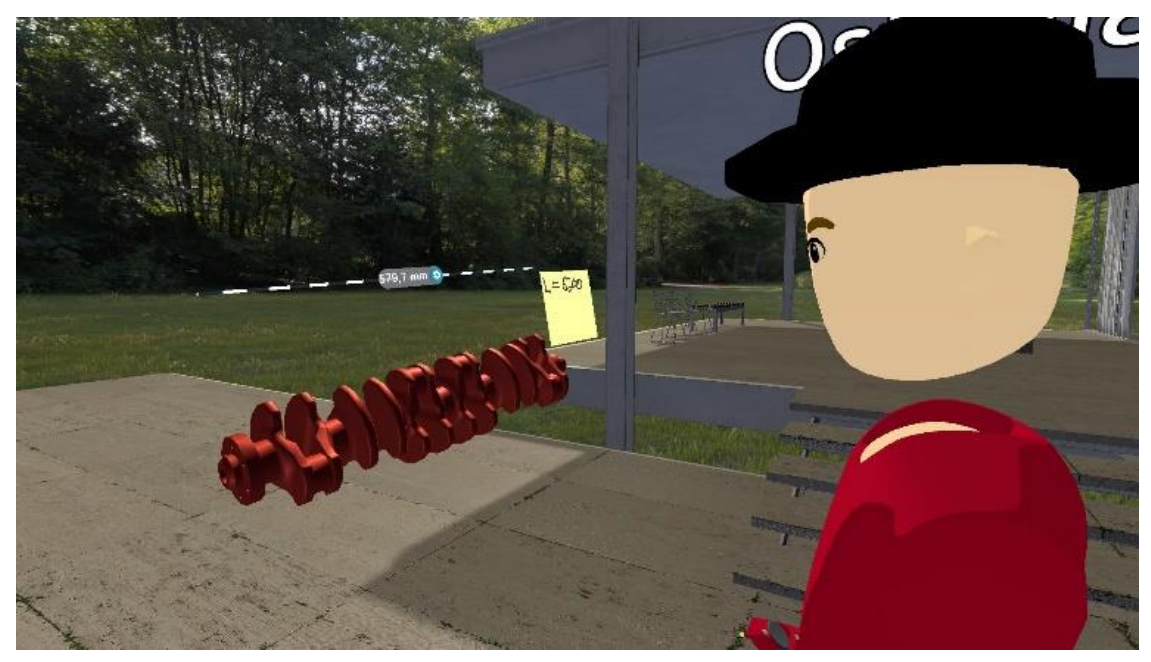

Figure 2. Design review conducted by the authors in VR 


\section{METHODOLOGY AND IMPLEMANTATION}

\subsection{General methodology}

In order to increase the proportion of VR-supported methods in product development, it is first necessary to analyse which methods are suitable for VR. According to current literature, following factors play a decisive role for the use of VR technology:

- $\quad$ Number of participants (Orsolits and Lackner, 2020)

- Team composition (Orsolits and Lackner, 2020)

- $\quad$ Degree of team interaction (Orsolits and Lackner, 2020)

- Complexity of the presentation (Freeman et al., 2018)

- Used method class (Orsolits and Lackner, 2020)

According to the authors, the "complexity of the method" is another important factor. In the methods used in product development, each of these properties occurs in different specifications. These specifications have a decisive influence on whether a method is suitable for VR. In the following, the individual properties, their specifications and their influence on the VR suitability are described evaluated. If a specification is well VR suited, it is rated with two points. If it is partially suitable, it is awarded one point. If the specification is not suitable for VR implementation, no point is awarded.

\section{Number of participants}

The number of participants varies according to the selected method. Individuals are well suited to perform highly specialised methods such as creating 3D models. Creative and communicative tasks are carried out in small groups of 2-4 people. Results that should cover a broad spectrum are determined by groups of 5-7 participants. Larger groups are usually not used.

When using VR in team processes, team size plays a decisive role. For individuals, the effort required to prepare a VR meeting is often too big. The implementation of such methods with the help of VR is therefore not advisable. For larger groups (5-7) VR is generally suitable, but the requirements for software operation and the communication of the participants is challenging. For example, it can be difficult to know exactly which person is being addressed. At the same time, problems can arise in identifying the addressed person. The reason for this is that not all communication channels such as gestures or facial expressions can be used. Methods that rely on large groups can therefore only be executed with VR tools to a limited degree. Methods that rely on small groups can be carried out excellently with VR technology. The effort for the preparation of the VR-session is reasonable for the individual person. Furthermore, communication problems occur less often in smaller groups.

\section{Team composition}

When carrying out activities, the team composition plays a decisive role. If all team members come from the same discipline, they can draw on a vocabulary recognised within the discipline. In the case of a team working together on an interdisciplinary basis, this has to be established first so that misunderstandings can arise, especially in the forming phase. In both cases, the method can be performed using VR technology. The advantages offered by VR are more important for interdisciplinary teams, as lack of understanding can be eliminated with the help of 3D views and examples. Complicated verbal explanations are not necessary. Accordingly, the realisation of interdisciplinary methods with the help of VR is considered as more suitable.

\section{Degree of team interaction}

There are methods in which the individual process steps are handled by individual team members alone. The interaction during the execution of these steps is accordingly low. In methods where the individual process steps are processed simultaneously by several team members, the interaction is therefore high. In both cases, it is conceivable that the task is carried out with the help of the VR. However, the full potential is unfolded with a high degree of interaction. Therefore, such methods are better suited for VR implementation.

\section{Complexity of the presentation}

Another property is the way in which given information is transferred. Here we differentiate between verbal conversations, 2D representations, such as lists or sketches, and 3D representations of components, assemblies or entire plants. Their full potential can only be developed in the 3-D representation, since in contrast to the conventional screen representation it is possible to walk around the model. 2D objects can also be displayed in VR, but there are no advantages compared to 
conventional display methods such as whiteboards or PC screens. Due to the high set-up effort, VR is not suitable for information transfer based purely on verbal discussions.

\section{Used method classes}

According to (Daenzer and Haberfellner, 1999), methods can be classified in three categories:

- The first class of methods is called "analysis and objective setting". Here, either the current situation is analysed on the basis of an external goal, or a goal is formulated on the basis of the analysed situation. Due to the general approach, for example in the context of literature and patent searches, this method can only be supported by VR to a limited extent.

- The second method class is "Development of solution ideas". Here, solution ideas are developed according to previously defined requirements. Since the different solution specifications are often available as 2D or 3D objects, VR is well suited to support methods of these classes. The use of VR improves the understanding of the model and the interaction between different system elements.

- Evaluation procedures and decision-making techniques form the third class of methods. Within the framework of these methods, the previously developed solution ideas are evaluated and ultimately the most suitable one is selected. To ensure a certain degree of objectivity, these procedures are often carried out jointly by team members.

\section{Method complexity}

- Method complexity can be understood as the degree to which individual process steps and used tools influence each other. Methods that involve very complex procedures are suitable for implementation with the help of VR (Oprean et al., 2018). Accordingly, complex methods are particularly suitable for the implementation of VR. VR can also be used for methods with low complexity. Here, the use of VR can lead to the circumstance that methods that are actually simple to perform are unnecessarily complicated by the use of an additional tool.

Table 1 shows all method characteristics and their respective specifications. In the right column each specification is assigned a value regarding the influence on the VR capability of a method. In the next section we explain the procedure for the evaluation of methods by means of some examples.

Table 1. Characteristics of methods and their specifications

\begin{tabular}{|c|c|c|c|c|c|}
\hline Characteristics & Specifications & $\begin{array}{l}\text { suitable } \\
\text { for VR }\end{array}$ & Characteristics & Specifications & $\begin{array}{l}\text { suitable } \\
\text { for VR }\end{array}$ \\
\hline \multirow{3}{*}{$\begin{array}{l}\text { Number of } \\
\text { Participant }\end{array}$} & 1 & 0 & \multirow{3}{*}{$\begin{array}{l}\text { Complexity of } \\
\text { the presentation }\end{array}$} & Verbal conversations & 0 \\
\hline & 2 to 4 & 2 & & 2D-Presentations & 1 \\
\hline & 5 to 7 & 1 & & 3D-Presentations & 2 \\
\hline \multirow{3}{*}{$\begin{array}{l}\text { Team } \\
\text { composition }\end{array}$} & Same discipline & 1 & \multirow{3}{*}{ Method classes } & $\begin{array}{l}\text { Analysis and target } \\
\text { setting }\end{array}$ & 1 \\
\hline & Interdisciplinary & 2 & & $\begin{array}{l}\text { development of } \\
\text { solutions }\end{array}$ & 2 \\
\hline & - & - & & $\begin{array}{l}\text { Evaluation } \\
\text { procedures and } \\
\text { decision }\end{array}$ & 2 \\
\hline \multirow{2}{*}{$\begin{array}{l}\text { Degree of } \\
\text { team } \\
\text { interaction }\end{array}$} & Low & 1 & \multirow{2}{*}{$\begin{array}{l}\text { Method } \\
\text { complexity }\end{array}$} & Low & 1 \\
\hline & High & 2 & & High & 2 \\
\hline
\end{tabular}

\subsection{Application of the assessment method}

If a method is selected to perform one of the activities listed in VDI 2221 depends on different factors. The size of the company and the complexity of the product play an important role. Equally important is the development task itself, i.e. whether it is a new, adaptation or variant development.

The subject of this case study is a schematic, global mechanical engineering company. With a share of $40 \%$, newly developed products make up the majority of the development work. Accordingly, the company uses only a few methods that are suitable for the specific application. Further details on the 
described application case can be found in VDI 2221_2 (Verein Deutscher Ingenieure, 2019). In the context of this paper, a method selection was made according to the subject of the case study within the phases "search for solution principles and their structures" and "evaluation and selection of the solution concept". In addition to the methods described, further methods from other phases of product development were evaluated. Due to their scope, these are not presented in detail.

\section{Searching for solution principles and their structures}

The search for solutions and their structures is the third phase in product development after VDI 2221. Creative methods such as brainstorming, method 635 or morphological analysis are used here. Using these methods, it is possible to generate a wide range of different solution variants. In order to illustrate the application of the methodology presented above, it is executed exemplarily on the morphological analysis.

Morphological analysis belongs to the method class of development of solutions (2 Points). Here an interdisciplinary team ( 2 Points) of up to 5 members ( 2 Points) work together to solve a problem. The goal is to capture the complex problem as precisely as possible and generate a large number of different possible solutions. For this purpose, the main problem is first broken down into several sub problems that are easier to solve (1 Point). For these sub problems, individual solutions are then listed, which are listed in a matrix (1 Point). The partial solutions developed are then combined with each other, resulting in overall solutions with different characteristics. The partial solutions developed are then combined with each other, resulting in overall solutions with different characteristics. This process is very dynamic and involves close cooperation between the employees (2 Points). If one evaluates the mentioned characteristics of the morphological analysis according to the methodology presented before, the method is well suited for VR with 10 out of 12 possible points.

In table two, morphological analysis is compared to brainstorming and method 635. The other two methods were evaluated in the same way. As you can see, brainstorming reached a similarly high value according to the applied methodology. However, the method 635 is less suitable for VR. One reason for this is that only members of the domain are used for this method. This is necessary because the solution steps build on each other and extend the previous solution. If employees from different fields come together here, misunderstandings can quickly arise. In addition, the solution steps take place one after the other, so that the advantages offered by VR when working together are not fully used.

If a company would like to carry out the presented phase VR-supported, the morphological analysis is recommended for the execution, as it is best suited for VR support.

Table 2. Common methods in phase 3 of VDI 2221

\begin{tabular}{|c|c|c|c|c|c|c|}
\hline $\begin{array}{l}\text { Number of } \\
\text { Participant }\end{array}$ & $\begin{array}{c}\text { Team } \\
\text { composition }\end{array}$ & $\begin{array}{l}\text { Degree of } \\
\text { team } \\
\text { interaction }\end{array}$ & $\begin{array}{l}\text { Complexity of the } \\
\text { presentation }\end{array}$ & $\begin{array}{l}\text { Method } \\
\text { classes }\end{array}$ & $\begin{array}{l}\text { Method } \\
\text { comple } \\
\text { xity }\end{array}$ & $\begin{array}{l}\text { Total } \\
\text { score }\end{array}$ \\
\hline \multicolumn{7}{|c|}{ Morphological analysis } \\
\hline 2 to 5 & $\begin{array}{c}\text { Interdiscipli } \\
\text { nary }\end{array}$ & High & 2D-Presentation & $\begin{array}{c}\text { development } \\
\text { of solutions }\end{array}$ & low & $\begin{array}{c}10 \text { of } \\
12 \\
\end{array}$ \\
\hline \multicolumn{7}{|c|}{ Method 635} \\
\hline 6 & $\begin{array}{c}\text { Same } \\
\text { discipline }\end{array}$ & low & 2D-Presentation & $\begin{array}{c}\text { development } \\
\text { of solutions }\end{array}$ & high & 8 of 12 \\
\hline \multicolumn{7}{|c|}{ Brainstorming } \\
\hline any & $\begin{array}{c}\text { Interdiscipli } \\
\text { nary }\end{array}$ & low & 2D-Presentation & $\begin{array}{l}\text { development } \\
\text { of solutions }\end{array}$ & low & 9 of 12 \\
\hline
\end{tabular}

Assessing and selecting the solution concept

In the fourth phase of product development the developed solution concepts are assessed and selected. Here the methods, "weighted point evaluation", "pairwise comparison" and the SWOT analysis were examined for VR suitability. These methods are mainly used in companies that develop a lot of new products. Table 3 shows the results according to the methodology developed.

It turns out that the selected methods are not or only partially suitable for VR. In evaluation processes, teamwork is limited to discussing the individual evaluation results of the team members. The actual evaluation is done by each individual member on his/her own. 
In order for VR to be helpful for the evaluation, rudimentary 3D models of the solutions must already exist at this point. If these are then displayed spatially in VR, it is easier for the team members to evaluate the individual partial solutions. In order to be able to carry out the described phase with VR support, the company processes as well as the methods used must first be adapted.

Table 3. Common methods in phase 4 of VDI 2221

\begin{tabular}{|c|c|c|c|c|c|c|}
\hline $\begin{array}{c}\text { Number } \\
\text { of } \\
\text { Participant }\end{array}$ & $\begin{array}{c}\text { Team } \\
\text { composition }\end{array}$ & $\begin{array}{c}\text { Degree of } \\
\text { team } \\
\text { interaction }\end{array}$ & $\begin{array}{c}\text { Complexity } \\
\text { of the } \\
\text { presentation }\end{array}$ & $\begin{array}{c}\text { Method } \\
\text { classes }\end{array}$ & $\begin{array}{c}\text { Method } \\
\text { complexity }\end{array}$ & Total score \\
\hline \multicolumn{7}{|c|}{ Weighted point rating } \\
\hline 3 to 7 & Interdisciplinary & low & $\begin{array}{c}\text { 2D- } \\
\text { Presentation }\end{array}$ & $\begin{array}{c}\text { Evaluation } \\
\text { procedure }\end{array}$ & low & 7 of 12 \\
\hline 6 & Same discipline & low & $\begin{array}{c}\text { 2D- } \\
\text { Presentation }\end{array}$ & $\begin{array}{c}\text { Evaluation } \\
\text { procedure }\end{array}$ & low & 5 of 12 \\
\hline \multicolumn{7}{|c|}{ Brainstorming } \\
\hline 3 to 7 & Interdisciplinary & low & $\begin{array}{c}\text { 2D- } \\
\text { Presentation }\end{array}$ & $\begin{array}{c}\text { Evaluation } \\
\text { procedure }\end{array}$ & low & 7 of 12 \\
\hline
\end{tabular}

\section{CONCLUSION AND OUTLOOK}

In addition to the presented methods, further typical methods along the entire product development process were evaluated in accordance with the procedure described in Chapter 3.1. The final scores can be found in Table 4. Activities marked in green can already be performed with VR support. To perform the methods marked in yellow, existing VR solutions must be improved and adapted. For all methods marked in orange, it is sufficient to adapt the method itself to VR use. All activities marked in red can neither be supported by a VR adaptation nor by a method adaptation.

As can be seen, only about 15 percent of all product development methods can currently be carried out with the help of VR technology. If suitable methods are adapted to VR, it is possible to increase this value to about 50 percent. In order to reach the required 60 percent, existing VR solutions must also be adapted to the corresponding methods. In this way, a maximum coverage of 74 percent can be achieved. Based on this, the following research fields can be defined for the future.

\section{Adaptation of methods}

In order to adapt existing methods to possible VR support, the sometimes very strict procedure that these methods exhibit must be broken down and replaced by dynamic processes. Designing rough 3D models at an early stage helps to speed up decision-making processes, especially during the first phases. Designing rough 3D models at an early stage helps to speed up decision-making processes, especially during the first phases. The adaptation of these methods and the guarantee of continuous data availability across all tools used (also outside of VR) are the greatest challenges here. In order to solve these, intensive research will be required in the future.

\section{VR adjustments}

In order to adapt existing VR software solutions to the methods, new functions such as the creation and export of solid models must first be implemented. In addition to these new functions, future research work must focus on the development of a uniform, ergonomically usable GUI (graphical user interface). Furthermore, it must be evaluated how the newly developed tools can be optimally integrated into existing company processes.

Table 4. Overview of common product development methods and their evaluation for VR suitability

\begin{tabular}{|c|c|c|c|c|c|}
\hline \multicolumn{2}{|c|}{$\begin{array}{c}\text { Clarification of problem } \\
\text { and task }\end{array}$} & \multicolumn{2}{|c|}{$\begin{array}{c}\text { Assessment and } \\
\text { selection of solution } \\
\text { concepts }\end{array}$} & \multicolumn{2}{|c|}{$\begin{array}{c}\text { Integrating of product as a } \\
\text { whole }\end{array}$} \\
\hline Method & Score & Method & Score & Method & Score \\
\hline
\end{tabular}




\begin{tabular}{|c|c|c|c|c|c|c|}
\hline $\begin{array}{c}\text { Product } \\
\text { questionnaire }\end{array}$ & 6 & $\begin{array}{l}\text { Weighted } \\
\text { point rating }\end{array}$ & 7 & $\begin{array}{l}\text { optimisation of } \\
\text { sub-elements }\end{array}$ & 8 & $\begin{array}{c}\text { VR } \\
\text { suitable }\end{array}$ \\
\hline $\begin{array}{c}\text { Search } \\
\text { matrices }\end{array}$ & 7 & $\begin{array}{l}\text { Pair-By- } \\
\text { comparison }\end{array}$ & 5 & Fine design & 8 & $\begin{array}{l}\text { Adjust } \\
\text { VR }\end{array}$ \\
\hline $\begin{array}{l}\text { Association } \\
\text { lists }\end{array}$ & 7 & $\begin{array}{l}\text { SWOT- } \\
\text { Analysis }\end{array}$ & 7 & Designreview & 12 & $\begin{array}{l}\text { Adjust } \\
\text { Method }\end{array}$ \\
\hline \multicolumn{2}{|c|}{$\begin{array}{c}\text { Determination of } \\
\text { functions and their } \\
\text { structures }\end{array}$} & \multicolumn{2}{|c|}{$\begin{array}{c}\text { Subdivision into } \\
\text { modules, interface } \\
\text { definition }\end{array}$} & \multicolumn{2}{|c|}{$\begin{array}{l}\text { Elaboration of execution } \\
\text { and usage requirements }\end{array}$} & $\begin{array}{l}\text { Not VR } \\
\text { suitable }\end{array}$ \\
\hline Method & Score & Method & Score & Method & Score & \\
\hline Function lists & 8 & $\begin{array}{c}\text { Design } \\
\text { structure } \\
\text { matrix }\end{array}$ & 7 & $\begin{array}{l}\text { Assembly } \\
\text { instructions }\end{array}$ & 6 & \\
\hline $\begin{array}{l}\text { Functional } \\
\text { structure } \\
\text { Pahl/Beitz } \\
\end{array}$ & 8 & $\begin{array}{l}\text { Allocated } \\
\text { Volume }\end{array}$ & 9 & Documentation & 6 & \\
\hline $\begin{array}{c}\text { General } \\
\text { functional } \\
\text { structure } \\
\end{array}$ & 8 & $\begin{array}{l}\text { SysML } \\
\text { diagrams }\end{array}$ & 5 & $\begin{array}{l}\text { Instruction } \\
\text { manual }\end{array}$ & 6 & \\
\hline \multicolumn{2}{|c|}{$\begin{array}{l}\text { Search for solution } \\
\text { principles and their } \\
\text { structures } \\
\end{array}$} & \multicolumn{2}{|c|}{ Shaping of modules } & \multicolumn{2}{|c|}{$\begin{array}{l}\text { assurance of fulfilment of } \\
\text { requirements }\end{array}$} & \\
\hline Method & Score & Method & Score & Method & Score & \\
\hline $\begin{array}{c}\text { Morphological } \\
\text { analysis }\end{array}$ & 10 & $\begin{array}{c}\text { Shape } \\
\text { studies }\end{array}$ & 8 & $\begin{array}{l}\text { Ergonomic } \\
\text { studies }\end{array}$ & 11 & \\
\hline Method 635 & 8 & $\begin{array}{c}\text { Preliminary } \\
\text { draft }\end{array}$ & 10 & simulation & 10 & \\
\hline Brainstorming & 9 & $\begin{array}{l}\text { Rough } \\
\text { design }\end{array}$ & 9 & calculation & 6 & \\
\hline
\end{tabular}

\section{ACKNOWLEDGEMENTS}

The authors gratefully thank the Ministry of Science and Culture of the German state of Lower Saxony for funding the project "Innovation Plus - Virtual Teams in Higher Education".

\section{REFERENCES}

Abdelhameed, W.A. (2013), "Virtual Reality Use in Architectural Design Studios: A Case of Studying Structure and Construction”, Procedia Computer Science, Vol. 25, pp. 220-230.

Anthes, C., Garcia-Hernandez, R.J., Wiedemann, M. and Kranzlmuller, D. (2016), "State of the art of virtual reality technology", in 2016 IEEE Aerospace Conference: 5-12 March 2016, 05.03.2016 - 12.03.2016, Big Sky, MT, USA, IEEE, Piscataway, NJ, pp. 1-19.

Balzerkiewitz, H.-P. and Stechert, C. (2020a), "The evolution of virtual reality towards the usage in early design phases", Proceedings of the Design Society: DESIGN Conference, Vol. 1, pp. 91-100.

Balzerkiewitz, H.-P. and Stechert, C. (2020b), "Use of Virtual Reality in Product Development by Distributed Teams”, Procedia CIRP, Vol. 91, pp. 577-582.

Berg, L.P. and Vance, J.M. (2017), “An Industry Case Study: Investigating Early Design Decision Making in Virtual Reality", Journal of Computational Design and Engineering, Vol. 17 No. 011001 // 1, pp. 1-7.

Daenzer, W.F. and Haberfellner, R. (Eds.) (1999), Systems engineering: Methodik und Praxis, 10., durchges. Aufl., erg. mit dem SE-Wissensbaum von Mario Becker, Verl. Industrielle Organisation, Zürich.

Dionisio, J.D.N., III, W.G.B. and Gilbert, R. (2013), "3D Virtual worlds and the metaverse", ACM Computing Surveys, Vol. 45 No. 3, pp. 1-38.

Freeman, I., Salmon, J. and Coburn, J. (2018), "A bi-directional interface for improved interaction with engineering models in virtual reality design reviews", International Journal on Interactive Design and Manufacturing (IJIDeM), Vol. 12 No. 2, pp. 549-560.

Gero, J.S. (1990), "Design Prototypes: A Knowledge Representation Schema for Design". 
Giorgio, A. de, Romero, M., Onori, M. and Wang, L. (2017), "Human-machine Collaboration in Virtual Reality for Adaptive Production Engineering", Procedia Manufacturing, Vol. 11, pp. 1279-1287.

Gong, L., Berglund, J., Fast-Berglund, Å., Johansson, B., Wang, Z. and Börjesson, T. (2019), "Development of virtual reality support to factory layout planning", International Journal on Interactive Design and Manufacturing (IJIDeM), Vol. 13 No. 3, pp. 935-945.

Hilfert, T. and König, M. (2016), "Low-cost virtual reality environment for engineering and construction", Visualization in Engineering, Vol. 4 No. 1, p. 8.

Kassem, M., Benomran, L. and Teizer, J. (2017), "Virtual environments for safety learning in construction and engineering: seeking evidence and identifying gaps for future research", Visualization in Engineering, Vol. 5 No. 1.

Kunkel-Razum, K. (2020), Duden - Die deutsche Rechtschreibung: Auf der Grundlage der aktuellen amtlichen Rechtschreibregeln, Duden, 28, völlig neu bearbeitete und erweiterte Auflage, Dudenverlag, Berlin.

Oprean, D., Simpson, M. and Klippel, A. (2018), "Collaborating remotely: an evaluation of immersive capabilities on spatial experiences and team membership", International Journal of Digital Earth, Vol. 11 No. 4, pp. 420-436.

Orsolits, H. and Lackner, M. (2020), Virtual Reality und Augmented Reality in der Digitalen Produktion, Springer Fachmedien Wiesbaden, Wiesbaden.

Orsolits, H. and Lackner, M. (2013), Pahl/Beitz Konstruktionslehre: Methoden und Anwendung erfolgreicher Produktentwicklung, 8., vollständig überarbeitete Auflage, Springer Vieweg, Berlin, Heidelberg.

Rademacher, M.H. (2014), Virtual Reality in der Produktentwicklung, Springer Fachmedien Wiesbaden, Wiesbaden.

Sutherland, I.E. (1968), "A head-mounted three dimensional display”, Fall Joint Computer Conference, pp. 757-764.

Verein Deutscher Ingenieure (2019), Design of technical products and systems: Model of product design No. 2221.

Wang, C.C.L., Magnenat-Thalmann, N. and Pan, Z. (Eds.) (2013), Proceedings of the 12th ACM SIGGRAPH International Conference on Virtual-Reality Continuum and Its Applications in Industry - VRCAI '13, ACM Press, New York, New York, USA.

Zaker, R. and Coloma, E. (2018), "Virtual reality-integrated workflow in BIM-enabled projects collaboration and design review: a case study", Visualization in Engineering, Vol. 6 No. 1, p. 230. 